\title{
PRÁCTICAS COMUNICATIVAS Y DESAFECCIÓN POLÍTICA EN EL CONTEXTO DE LAS CAMPAÑAS ELECTORALES. ANÁLISIS DE SU RELACIÓN DESDE EL MODELO O-S-R-O-R ${ }^{1}$
}

\begin{abstract}
COMMUNICATIVE PRACTICES AND POLITICAL DISAFFECTION IN THE CONTEXT OF ELECTION CAMPAIGNS. RELATIONSHIP ANALYSIS USING THE O-S-R-O-R MODEL
\end{abstract}

\section{Carlos Muñiz}

| carlos.munizm@uanl.mx |

Universidad Autónoma de Nuevo León, México

Resumen: Es habitual encontrar en buena parte de los países democráticos cada vez más ciudadanos alejados de la política, con desconfianza en las instituciones y que incluso llegan a deslegitimar el sistema. Son diversos los factores que determinan esta desafección política, presente a través de manifestaciones de cinismo, apatía y escepticismo. Entre ellos, se ha apuntado a la posible influencia de los hábitos comunicativos, es decir consumo de medios y conversación sobre política, tanto en el ámbito offline como en el online. Para determinar este posible efecto, se realizó una encuesta panel en el transcurso de las pasadas elecciones presidenciales de México de 2018. Tomando el modelo O-S-R-O-R como referencia, los resultados muestran una nula influencia de los hábitos comunicativos en el desarrollo de cinismo y más limitado en el de escepticismo. Sin embargo, se observa un aumento de la apatía derivado del consumo de medios tradicionales y del desarrollo de conversación interactiva. Palabras clave: desafección política; consumo mediático; conversación política; modelo O-S-R-O-R; campañas electorales.

[01] Esta investigación fue financiada con los proyectos del Consejo Nacional de Ciencia y Tecnología (CONACYT) titulados «Análisis de la cobertura mediática de las campañas electorales y su impacto en la desafección política y el compromiso democrático ciudadano» (Clave 280739) e «Infoentretenimiento político, encuadres periodísticos y desconfianza ciudadana» (Clave 256670). 


\begin{abstract}
It is common to find in many democratic countries more and more citizens away from politics, with distrust in institutions and even delegitimizing the political system. There are several factors that may determine this political disaffection, which makes present through manifestations of cynicism, apathy and skepticism. Among them, the possible influence of both offline and online communication habits, such as media consumption and political conversation, has pointed out. To determine this possible effect, a panel survey was carried out during the last 2018 presidential elections in Mexico. Considering the O-S-R-O-R model as a reference, findings show a null influence of communication habits in the development of cynicism and a limited effect on the skepticism. However, there was an increase in apathy derived from both the consumption of traditional media and the development of interactive conversation. Keywords: Political Disaffection; Media Consumption; Political Conversation; O-S-R-O-R Model; Election Campaigns.
\end{abstract}

\title{
1. Introducción
}

Es ya habitual encontrar en la literatura desde hace varias décadas un debate acerca del incremento que se está produciendo en buena parte de las sociedades occidentales de una ciudadanía cada vez más alienada y menos comprometida a nivel político (Delli Carpini, 2000). Una realidad que, por desgracia, es común en muchas de las democracias (Rijkhoff, 2018; Yamamoto y Kushin, 2014) y que no deja de arrojar interrogantes sobre el futuro que espera a estos sistemas ante la presencia de capas cada vez más grandes de la población con actitudes negativas hacia el sistema político en su conjunto. No en vano, es uno de los problemas más importantes que enfrenta la democracia, por el posible debilitamiento que para la misma puede suponer la presencia de este tipo de ciudadanía (Dalton, 2004; Luján Ponce y García Villanueva, 2007; Pharr y Putnam, 2000).

Estas manifestaciones dejan entrever una cada vez mayor desafección política entre la ciudadanía, un concepto que en la literatura científica ha sido habitualmente asimilado al cinismo político. Esta desafección viene determinada por una falta de confianza en las instituciones, un alejamiento de la política y un sentimiento de incapacidad para influir en el sistema (Torcal, 2002). Es decir, una disposición negativa hacia la política (Austin y Pinkleton, 1995), que a través de un proceso de espiral de desafección puede derivar en cualidades negativas — como cinismo, alienación, desconfianza y apatía (Corduneanu y Muñiz, 2011; Rijkhoff, 2018)—, o más bien en cualidades positivas - como el escepticismo - que pueden motivar la participación política (Yamamoto y Kushin, 2014).

El papel de los medios de comunicación, en especial durante las campañas electorales, y su influencia en la configuración de actitudes y comportamien- 
tos ciudadanos es una línea ampliamente estudiada dentro de la literatura de comunicación política (de Vreese, 2005; Rijkhoff, 2018; Yamamoto y Kushin, 2014). Dentro de los trabajos realizados para sistematizar este proceso, se ha esbozado el Modelo de Mediación Comunicativa (O-S-R-O-R) (Shah et al., 2007, 2017). En concreto, el modelo plantea la existencia de un efecto indirecto de la exposición mediática sobre la participación ciudadana, a través del desarrollo de orientaciones posteriores al consumo y razonamiento del mensaje. Si bien entre estas orientaciones potenciadas por los medios se han planteado normalmente el conocimiento y la eficacia política, es posible que también se pueda encontrar la desafección política (Choi, Warner y Jennings, 2018).

Teniendo ello en cuenta, este trabajo busca determinar si este proceso mediacional de influencia de orientaciones previas sobre orientaciones posteriores, como es la desafección, explicado desde el modelo O-S-R-O-R, se produce durante una campaña presidencial. Para ello, se toma como referencia el caso mexicano, y más en particular la campaña electoral presidencial de 2018. A partir de los datos de una encuesta de tipo panel de tres olas, con muestreo probabilístico, entre la población a nivel nacional, el presente artículo busca analizar la presencia de la desafección política entre la ciudadanía tras las elecciones. Asimismo, se pretende determinar si las variables de consumo mediático, tanto de medios tradicionales como digitales, y la conversación política offline y online afectaron en el cambio de la desafección política, de acuerdo con el modelo teórico propuesto.

\section{Acerca de la desafección política}

La ciudadanía juega un papel crucial en el fortalecimiento de los sistemas políticos y la propia democracia de los países, para lo que es necesario que cuente con la información suficiente y presente niveles elevados de sofisticación política (Dalton, 2006). Esto llevará a los ciudadanos a mantener un compromiso democrático fuerte, que se traducirá en un mayor interés por los aspectos políticos, conocimiento de los mismos y, finalmente, en el desarrollo de una participación política y cívica fuerte y comprometida (Delli Carpini, 2004). Sin embargo, es habitual encontrar en las actuales democracias altos niveles de desafección política entre la ciudadanía, que implica la coexistencia conjunta entre un apoyo ciudadano al sistema democrático con una falta de confianza en las instituciones, alejamiento de la política y sentimiento de incapacidad para influir en el sistema (Mora Heredia y Escobar Cruz, 2003; Torcal, 2002).

En años recientes los estudios realizados han puesto de manifiesto en las democracias occidentales, tomando la norteamericana como ejemplo, un aumento de la ciudadanía alienada y no comprometida (Delli Carpini, 2000). 
Este es un hecho común en muchas democracias (Yamamoto y Kushin, 2014), que ha llevado a plantear que en la actualidad se vive una época de descaro y desafección, donde una niebla de cinismo rodea a todo lo referido a la política y a la percepción de la actividad de los políticos (Rijkhoff, 2018: 333). Un hecho también presente en los países de Latinoamérica (Paramio, 2002) y México (Mora Heredia y Escobar Cruz, 2003), como lo ponen de manifiesto, por ejemplo, los datos de la Encuesta de Cultura Política y Prácticas Ciudadanas (Secretaría de Gobernación, 2012) o el 'Latinobarómetro' que lo sitúa como el país más insatisfecho con el funcionamiento de su democracia.

Más allá del hecho de la existencia o no de una falta de confianza y alejamiento ciudadano de la política, el problema se sitúa en que este fenómeno constituye uno de los principales problemas que enfrenta la democracia, por su posible impacto en el debilitamiento del sistema democrático (Dalton, 2004; Luján Ponce y García Villanueva, 2007; Pharr y Putnam, 2000). En este contexto, el concepto de desafección política toma relevancia, en tanto explica buena parte de este fenómeno de alejamiento respecto de la política que se puede observar en la mayor parte de los países occidentales, a través de actitudes ciudadanas como la desconfianza en instituciones y actores políticos, o incluso la deslegitimación del sistema político en su conjunto (Shah et al., 2017).

La desafección política constituye un concepto controvertido en la literatura científica, tanto en términos de su conceptualización como de su operacionalización (de Vreese, 2005; de Vreese y Semetko, 2002), que muchas veces ha sido asimilado al concepto de cinismo político. Además, normalmente se ha definido en oposición a la eficacia política, planteándose que está inversamente relacionado a la confianza en diferentes instituciones. Sin embargo, por parte de otros autores ha sido definido más bien como una disposición negativa hacia la política (Austin y Pinkleton, 1995), que puede reflejar el grado en que se desprestigia a la política y políticos, así como en qué medida estas palabras denotan algo negativo más que positivo (Agger, Goldstein y Pearl, 1961).

Sea como fuere, el concepto de desafección política encierra numerosas cualidades. Así, se puede asumir que la desafección contiene ciertas cualidades negativas, en tanto que implica la existencia de un público que presenta cinismo político. Es decir, alienación, disminución de la confianza en el gobierno y en la política, e incluso apatía (Corduneanu y Muñiz, 2011; Rijkhoff, 2018). En este sentido, se ha tomado como corazón del cinismo la falta de confianza ciudadana, considerándose que «la respuesta inicial del cínico es de desconfianza» (Cappella y Jamieson, 1997: 141). Por su parte, Torcal (2002) considera que el cinismo es un sentimiento generado por la ineficacia y la desafección 
políticas, lo que genera en la ciudadanía una falta de confianza en el proceso, en los políticos e instituciones, provocando su distanciamiento y alienación sin cuestionar la legitimidad del sistema.

Sin embargo, otros autores plantean que el cinismo va más allá de una simple desconfianza en el sistema (de Vreese y Semetko, 2002; Rijkhoff, 2018). Así, desde la comunicación política ha sido visto más como una brecha que se está abriendo entre los ciudadanos o incluso votantes y sus representantes políticos (Schuck, Boomgaarden y de Vreese, 2013). Pero, a pesar de que esta brecha supone un alejamiento ciudadano de la acción de los políticos, no necesariamente debe conllevar un resultado negativo. Y es que no todas las cualidades de la desafección política tienen que ser negativas, como la carga peyorativa que el término desafección podría hacer entender. En este sentido, se ha planteado la idea de la existencia de una espiral de desafección (Austin y Pinkleton, 1999) que puede derivar en efectos negativos o positivos.

Por una parte, se asume que los ciudadanos cínicos tienden a consumir menos —o directamente a no consumir - noticias y contenidos informativos para enterarse sobre política o los procesos electorales. Esto los llevaría a estar menos informados acerca de lo que ocurre en la esfera pública y, por consiguiente, la probabilidad de convertirse en ciudadanos apáticos y no participativos puede aumentar. Es decir, puede provocar que los ciudadanos generen indiferencia, falta de interés y/o pérdida de atención hacia la política (Yamamoto y Kushin, 2014), lo que derivaría en un menor compromiso y, por tanto, menor implicación con el sistema a través de los diferentes mecanismos de participación existentes.

Sin embargo, esta espiral también puede derivar en un efecto más positivo en el ciudadano. En este sentido, un mayor cinismo no necesariamente debe llevar a una pérdida de confianza, sino más bien a una vacilación acerca de si confiar o no en la información recibida desde el sistema político (Yamamoto y Kushin, 2014). Esto es, puede ser que se genere en la ciudadanía una incredulidad respecto del sistema, con tendencia a no creer el mensaje, lo que no implica necesariamente que se rechace el mismo. Más bien, el ciudadano tendrá mayores opciones para buscar información complementaria que le permita contrastar el mensaje recibido, lo que implica que el ciudadano se abre a la posibilidad de ser convencido en caso de recibir la información correcta.

Por tanto, nos encontramos ante un ciudadano desafecto que tiene escepticismo respecto de la realidad que percibe, y que, por ello, se informa sobre ésta para contrastar la información recibida con la posteriormente localizada, lo que supone una característica positiva de la desafección política. De esta manera, es posible que la existencia de un ciudadano desafecto comprometido (Muñiz y 
Maldonado, 2011) que, aun presentando dudas con respeto al sistema, sin embargo, participa del mismo a través de los mecanismos que están a su disposición gracias a la información extra que obtiene. Algo que podría explicar que los niveles de insatisfacción con la democracia que se perciben en países como México respondan más a la existencia de una ciudadanía con sentido crítico y democrático que a una ciudadanía políticamente cínica (Ackerman, 2012). Teniendo ello en cuenta, el artículo se plantea la siguiente pregunta de investigación:

$\rightarrow$ PI1: ¿Las relaciones entre cinismo, apatía y desafección detectadas en los ciudadanos permiten concluir más en una espiral de desafección positiva o negativa?

\section{Medios de comunicación y desafección política}

Un funcionamiento eficiente del sistema democrático necesita contar, necesariamente, con un público bien informado en el ámbito de la política y de los asuntos políticos (Dimitrova y Strömbäck, 2012). Para que esta sofisticación política ciudadana se produzca es trascendental el papel de los medios de comunicación, a través de su concurso en la transmisión de información política a la ciudadanía, lo que los convierte en piezas claves para el desarrollo democrático de los países (Avery, 2009; Trejo, 1994). No en vano, los medios son los encargados, en buena medida, de establecer puentes entre el sector político y gran parte de la sociedad que, sin su labor, no podría llegar a conocer o incluso entender los principales hechos acaecidos en la esfera política. Es decir, favorecen el aprendizaje político, lo que mejora el compromiso cívico de los ciudadanos (Kim, Russo, y Amnå, 2017; Lee, Shah, y McLeod, 2013).

Quizá uno de los momentos cruciales en la cobertura mediática de la política se trate de las campañas electorales, pues es un espacio en el que el debate entre los diferentes actores que conforman la esfera pública se acentúa. En los escenarios electorales los medios de comunicación constituyen mecanismos clave para la traslación y traducción de la realidad política a la ciudadanía (Martínez y Godínez, 2013). Sin embargo, se ha llegado a cuestionar si este ejercicio puede ocasionar efectos negativos en la ciudadanía. No en vano, datos como la disminución de confianza en las instituciones políticas y el incremento de la desafección política que se viene detectando en diferentes países, ha llevado a los investigadores a buscar explicaciones a este fenómeno en los cambios sociales y culturales o en la evolución de los partidos políticos y el partidismo (de Vreese y Semetko, 2002).

Una importante línea de estudio de este fenómeno se ha centrado en el papel jugado por los medios de comunicación. Dentro de esta línea de inves- 
tigación, se han esbozado dos paradigmas - hasta cierto punto contrapuestos- para explicar el efecto mediático. Por una parte, se plantea el efecto pernicioso que en la ciudadanía tiene el consumo de contenidos mediáticos sobre política, debido a la negatividad y conflicto que en ellos suelen dominar (Muñiz y Maldonado, 2011; Rojas, 2006). Este paradigma del malestar mediático (media malaise) comienza a configurarse en la academia norteamericana a partir de los años setenta del siglo $\mathrm{xx}$, tras la llegada de la televisión y tratando de dar respuesta a la creciente desconfianza en el sistema que se empezaba a encontrar entre la población (Avery, 2009; de Vreese, 2005).

Frente a esta postura pesimista, en los años noventa se abre, principalmente en la academia europea, una visión más positiva acerca de los posibles efectos del consumo mediático en las actitudes políticas de la ciudadanía (de Vreese, 2005; Rojas, 2006). Este nuevo paradigma, habitualmente conocido como de movilización mediática (political mobilization), asume que el consumo de ciertos medios, así como de ciertos contenidos transmitidos por éstos, no solamente no reduce, sino que puede incrementar el involucramiento político de los ciudadanos (Holtz-Bacha, 1990). Dentro de este paradigma ha destacado la Teoría del Círculo Virtuoso propuesta por Norris (2000), para quien las personas que sean más activas a nivel político tenderán a consumir mayores niveles de información política, lo que redundará en un mayor activismo y un despliegue de las actitudes positivas vinculadas al mismo.

Los estudios realizados hasta la fecha presentan resultados discordantes acerca de los efectos de los medios (Muñiz y Maldonado, 2011; Rojas, 2006), lo que parece implicar que los efectos son diferenciados en función de la exposición que se haga a diferentes medios y contenidos (Holtz-Bacha, 1990), planteándose que ambos paradigmas pueden ser complementarios entre sí (Avery, 2009). En relación con los hábitos de consumo de los medios tradicionales, como puede ser la exposición genérica a los medios o la atención a contenidos de política en los mismos, se ha detectado que la exposición a información tiende a generar menos alienación (Holtz-Bacha, 1990). Sin embargo, el consumo focalizado en contenidos de entretenimiento en medios tiende al mismo tiempo a generar más alienación entre la ciudadanía (Rojas, 2006).

Por su parte, se ha detectado que el consumo genérico de medios sociales tiende a hacer aumentar el cinismo y la apatía, salvo que se utilicen para obtener información, donde disminuye (Yamamoto y Kushin, 2014). Finalmente, y para el caso particular de México, donde se centra el presente artículo, el trabajo realizado por Muñiz y Maldonado (2011) permitió determinar un aumento de cinismo político entre los alumnos de bachillerato que a su vez presentaban mayores niveles de consumo de prensa escrita y que también tenían 
más confianza en noticias. Este resultado abre una posibilidad para cuestionar, a partir del planteamiento de la espiral de la desafección política antes explicada, la idea de la existencia de un cinismo comprometido, tendente al escepticismo y, por tanto, la búsqueda de información, más que a la apatía política.

Dentro del campo de la comunicación política son numerosos los estudios acerca del impacto mediático sobre las actitudes políticas de la ciudadanía. Tratando de sintetizar el efecto directo e indirecto que en este proceso se gene$\mathrm{ra}$, en los años noventa se planteó el Modelo de Mediación Comunicativa - $\mathrm{O}$ modelo O-S-O-R - que hipotetizaba sobre cómo el impacto de las variables comunicativas, tanto el consumo de medios masivos como la conversación interpersonal, afectaba la respuesta final de la audiencia que, por ejemplo, puede manifestarse en la participación ciudadana, pues se produce gracias a un proceso mediacional. Este mecanismo de mediación sería el jugado por las orientaciones posteriores, que se desarrollan tras la exposición o consumo de los estímulos comunicativos, y contribuyen a aumentar la participación gracias a un mayor conocimiento y eficacia del ciudadano.

Han sido muchos los autores que han estudiado este proceso, derivando en modificaciones continuas del modelo (al respecto ver Shah et al., 2017). Entre estas modificaciones se encuentra la de Shah et al. (2005), quienes incorporaron la reflexión como un elemento subsiguiente, y no simultáneo, al consumo de los contenidos de los medios. Sin embargo, el modelo que se ha aplicado en los estudios más recientes deriva de la reinterpretación realizada por Shah et al. (2007), planteando el nuevo Modelo de Mediación Comunicativa de Campaña - Modelo O-S-R-O-R - . La principal modificación radica en la incorporación que los autores hacen del 'Razonamiento' como una variable independiente entre el consumo de medios y las orientaciones posteriores.

Desde este planteamiento teórico se asume que las orientaciones iniciales del individuo $\left(\mathrm{O}_{1}\right)$, como puede ser el interés hacia la política o incluso algunas sociodemográficas, determinan qué y cuándo se consume en los medios, independientemente del tipo de medios y contenido del que se trate (Gil de Zúñiga, Bachmann, Hsu y Brundidge, 2013). Los mensajes de los medios que son consumidos por los sujetos constituyen el estímulo (S), gracias a los cuales se adquiere información dentro del proceso político, como por ejemplo puede ser una campaña electoral. Esta información obtenida a partir de la exposición a los diferentes medios sufrirá un proceso de Razonamiento $\left(\mathrm{R}_{1}\right)$, que implica el desarrollo de actividades tendentes a la discusión del contenido recibido desde los medios, tanto a un nivel intrapersonal como interpersonal, mediante la conversación con otras personas (Bakker y de Vreese, 2011; Shah et al., 2007; Yamamoto, Kushin y Dalisay, 2015). 
Gracias a ello, se generarán en el ciudadano una serie de orientaciones posteriores $\left(\mathrm{O}_{2}\right)$, lo que puede implicar, entre otros resultados, un aumento del conocimiento político que las personas tienen, pero también otras actitudes como la eficacia política o el cinismo político (Choi et al., 2018), entendido en este estudio como parte de la desafección política. Finalmente, se asume que estas variables en su conjunto, mediante un proceso de cadena causal, determinarán la manera y el nivel en que los ciudadanos se involucrarán en política (R). Este comportamiento se puede manifestar tanto en participación política online, como en la más tradicional participación política offline (Gil de Zúñiga, Jung y Valenzuela, 2012; Kim et al., 2017; Valenzuela, Park y Kee, 2009).

El modelo ha sido revisado recientemente por los autores Shah et al. (2017), atendiendo a la realidad actual donde el consumo mediático y la conversación política tienden a estar marcados por fuertes niveles de polarización política y partidismo. Esto los lleva a plantear que tanto el consumo mediático como la conversación pueden estar más o menos sesgados hacia diferentes posiciones políticas, generando que en ambos casos se produzcan hábitos selectivos de obtención de información y discusión de esta. Ello, a su vez, deriva no sólo en una participación política también sesgada, sino en posibles efectos perniciosos para la democracia, como puede ser un debilitamiento de la confianza en ciertos grupos sociales o instituciones, al ser percibidos como alineados con perspectivas ideológicas particulares que son contrarias a las que mantienen los ciudadanos, lo que puede redundar en una deslegitimación democrática del sistema político en su conjunto.

Diversos estudios han puesto a prueba este modelo causal, tanto a nivel internacional (Gil de Zúñiga et al., 2013; Jung, Kim y Gil de Zúñiga, 2011; Lee et al., 2013), como también en el contexto latinoamericano y mexicano (Muñiz y Corduneanu, 2014; Muñiz, Téllez y Saldierna, 2017; Saldierna, Marañón y Muñiz, 2015; Valenzuela, 2013). Sin embargo, estos estudios han tendido a centrarse en el proceso de explicación de la participación política utilizando como variables psicológicas mediadoras el conocimiento o la eficacia política, habitualmente consideradas como las orientaciones posteriores del modelo (Shah et al., 2007). Por el contrario, son escasos los trabajos que han utilizado variables como la desafección política, en cualquiera de sus tres dimensiones: cinismo, apatía y escepticismo políticos. 
Figura 1. Modelo teórico de los procesos mediacionales a estudiar.

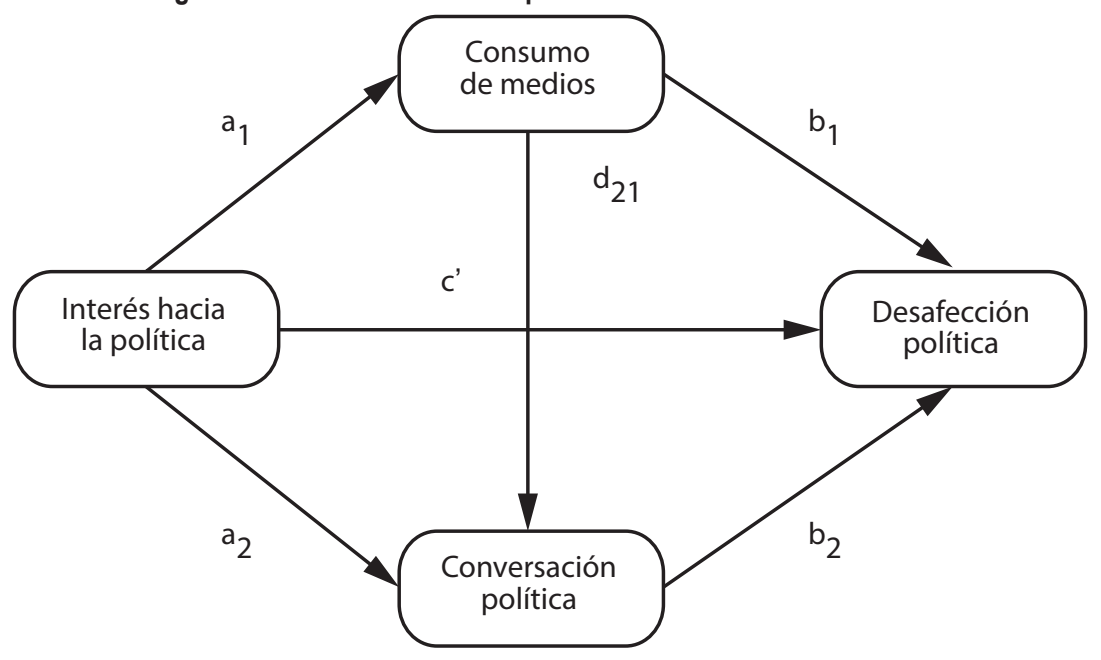

Fuente: elaboración propia.

Ello a pesar de que, como señalan en su revisión del modelo Shah et al. (2017), un resultado esperado del consumo mediático, en conjunción con la conversación sobre política, es la desconfianza en el sistema político, lo que en buena medida expresa la desafección política ciudadana (Torcal, 2002). Además, esta actitud puede entenderse como una orientación posterior, en la medida en tanto que ha sido definida como lo opuesto a la eficacia política (de Vreese, 2005; de Vreese y Semetko, 2002). Entre los pocos estudios previos realizados al respecto se observa el reciente de Choi, Warner y Jennings (2018), quienes han analizado el papel del cinismo como orientación posterior del modelo. Los autores detectaron un impacto limitado de la conversación política $(\mathrm{R})$ sobre el cinismo $\left(\mathrm{O}_{2}\right)$, no siendo estadísticamente significativo ninguno de los efectos indirectos donde el cinismo estuvo presente.

A partir de la evidencia aportada en los antecedentes empíricos revisados, se plantea un modelo teórico que se someterá a contraste, acerca del efecto indirecto del interés hacia la política sobre la desafección respecto de la misma de los ciudadanos (ver figura 1) y que plantea, por tanto, un modelo teórico O-S-R-O, con la desafección como variable final del modelo. Todo ello tomando como variables mediadoras el consumo de medios y la conversación política y estableciendo este orden de presencia dentro de la cadena causal analizada. En cuanto a la desafección, se sigue la propuesta de Yamamoto y Kushin (2014), quienes plantean que debe ser entendida como un concepto multidimensional, que engloba tanto cinismo, como apatía y escepticismo. Por ello, en el artículo se plantearon dos modelos teóricos para cada variable criterio, en función de si las variables mediadoras eran 
offline u online. Así pues, en el estudio se tratará de dar respuesta a las siguientes hipótesis y preguntas de investigación:

$\rightarrow \mathrm{H} 1$ : No existe un efecto indirecto del interés hacia la política sobre el cismo a través del consumo de medios tradicionales y la conversación política interpersonal.

$\rightarrow$ PI2: ¿Se produce un efecto indirecto del interés hacia la política sobre la apatía a través del consumo de medios tradicionales y la conversación política interpersonal?

$\rightarrow$ PI3: ¿Se produce un efecto indirecto del interés hacia la política sobre el escepticismo a través del consumo de medios tradicionales y la conversación política interpersonal?

$\rightarrow \mathrm{H} 2$ : No existe un efecto indirecto del interés hacia la política sobre el cismo a través del consumo de medios sociales y la conversación política interactiva.

$\rightarrow$ PI4: ¿Se produce un efecto indirecto del interés hacia la política sobre la apatía a través del consumo de medios sociales y la conversación política interactiva?

$\rightarrow$ PI5: ¿Se produce un efecto indirecto del interés hacia la política sobre el escepticismo a través del consumo de medios sociales y la conversación política interactiva?

\section{Método seguido}

\subsection{Diseño y muestra}

Para la realización de este estudio, se trabajó con un diseño metodológico explicativo bajo el método de encuesta panel, la cual permite analizar no sólo opiniones y actitudes de una población como en una encuesta descriptiva transversal, sino también el cambio que se produce en las mismas a lo largo del tiempo, y determinar las variables que afectan en ese cambio (Boomgaarden y Kritzinger, 2017; de Vreese y Semetko, 2002). Se considera que este diseño panel es el que permite cumplir adecuadamente los objetivos del artículo, ya que permite evaluar desde un enfoque longitudinal el modelo propuesto, midiendo en cada ola las diferentes variables intervinientes en el mismo. Para la realización del estudio, se contrató a la empresa demoscópica Survey Sampling International 
(SSI), con el objeto de contar con una muestra amplia y representativa de la población mexicana, a la par de garantizar la participación de los mismos participantes en las diferentes olas del estudio.

La primera ola se realizó la semana previa al inicio oficial de elecciones, comenzando el 23 de marzo y terminando el trabajo de campo el 30 de marzo. En dicha aplicación se levantaron un total de 1.819 entrevistas en línea. La segunda ola se realizó durante el mes de junio de 2018, con el objetivo de registrar actitudes y comportamientos con respecto a los primeros dos meses de campaña electoral. El levantamiento se realizó entre el 1 y el 25 de junio de 2018, participando finalmente una muestra de 996 entrevistados en la ola primera. La última aplicación se realizó una vez pasada la elección y cuando los conteos distritales de las elecciones presidenciales quedaron realizados, por lo que el trabajo de campo comenzó el 9 de julio y terminó el 19 de ese mes. En total participaron 701 entrevistados que también contestaron la primera y segunda ola.

De los datos obtenidos, únicamente se contó con los relativos a los participantes que fueran mayores de edad ( $\geq 18$ años) y censados como votantes en la República. En este sentido, en la muestra final $(N=701)$ participaron ciudadanos de todos los estados de la República, así como de Ciudad de México. Un 54.8 por ciento de la muestra estaba constituido por hombres $(n=384)$, por un 45.2 por ciento de mujeres $(n=317)$, con edades comprendidas entre 18 y 80 años $(M=42.07 ; D E=13.37)$. En la muestra se contemplaron participantes con diferentes niveles educativos, siendo el grupo mayoritario el correspondiente a aquellos que tenían estudios profesionales ( $n=424 ; 60.7$ por ciento) o de preparatoria ( $n=130 ; 18.6$ por ciento). Asimismo, un 43.6 por ciento de participantes reportaron unos ingresos mensuales ${ }^{2}$ de entre $\$ 10,001.00$ y $\$ 30,000.00(n=285)$, un 40 por ciento menores a $\$ 10,001.00(n=202)$ y un 25.4 por ciento más de $\$ 30,001.00(n=166)$.

\subsection{Medidas utilizadas}

Interés Político. Siguiendo la escala propuesta por Muñiz y Maldonado (2011), se les preguntó a los participantes acerca de su interés por la política local o municipal, la política a nivel estatal, la política a nivel nacional o federal y, finalmente, la política internacional. Para ello, se utilizaron escalas de Likert de 5 puntos que oscilaban entre nada interesado (1) y muy interesado (5) en cada reactivo, a fin de poder generar un indicador de interés general hacia la política. Se evaluó la consistencia interna de esta nueva escala, obteniéndose un buen resultado $(M=4.03 ; D E=0.94 ; \alpha=.88)$.

[02] Expresados en pesos mexicanos. 
Consumo de medios tradicionales. Con el objetivo de crear un indicador de seguimiento de medios tradicionales para informarse de las elecciones presidenciales, se preguntó a los participantes cuántos días a la semana habían leído en papel los periódicos La Jornada, Reforma, Excélsior, Milenio y ElUniversaly habían visionado los noticieros matutinos, asícomolosnocturnos, de las cadenas de televisión Las Estrellas de Televisa, TV Azteca 1 e Imagen TV $(M=1.91 ; D E=1.66 ; \alpha=.92)$.

Seguimiento de medios sociales. Se solicitó a los participantes que indicaran con qué frecuencia habían utilizado ciertos medios sociales para informarse de la campaña presidencial, a través de una escala de Likert, que oscilaba entre nunca (1) y muy frecuentemente (5), para cada una de las distintas variables. En concreto, se les pidió que señalaran acerca de su uso de páginas de Internet sobre política, así como el seguimiento de información en las siguientes redes sociales: Facebook, Twitter, YouTube, Instagram y WhatsApp $(M=2.96 ; D E=1.15 ; \alpha=.84)$.

Conversación política interpersonal. Se evaluó con una escala tipo Likert de 5 puntos, que oscilaba entre nunca (1) y todos los días (5), el grado de conversación con miembros de su familia, compañeros de trabajo, de clase, de clubes, etc., vecinos con los que tenían relación cercana, amigos y conocidos. Para completar esta escala, se tomaron dos ítems utilizados en su estudio por Shah et al. (2007), para medir el grado en que los encuestados conversaban sobre política con personas con las que coinciden en ideas políticas y con ideas distintas a las suyas $(M=2.94 ; D E=0.94 ; \alpha=.91)$.

Tabla 1. Datos descriptivos de las variables del Modelo O-S-R-O-R.

\begin{tabular}{|l|r|r|r|r|r|r|}
\hline & \multicolumn{1}{c|}{ Ola } & \multicolumn{1}{c}{ Mín. } & \multicolumn{1}{c|}{ Máx. } & \multicolumn{1}{c|}{ ME } \\
\hline Interés Político & 1 & 1 & 5 & 4.03 & 0.94 & .88 \\
\hline Seguimiento de medios sociales & 2 & 1 & 5 & 2.96 & 1.15 & .84 \\
\hline Consumo de medios tradicionales & 2 & 0 & 7 & 1.91 & 1.66 & .92 \\
\hline Conversación política interpersonal & 2 & 1 & 5 & 2.94 & 0.94 & .91 \\
\hline Conversación política interactiva & 2 & 1 & 5 & 2.47 & 1.18 & .90 \\
\hline Cinismo político & 3 & 1 & 6 & 4.81 & 0.98 & .89 \\
\hline Apatía política & 3 & 1 & 6 & 3.12 & 1.14 & .73 \\
\hline Escepticismo político & 3 & 1 & 6 & 4.83 & 0.92 & .92 \\
\hline
\end{tabular}

Nota: $N=701$. Todas las variables se midieron con escalas de Likert de 5 ó 6 puntos, excepto el consumo de medios tradicionales durante la campaña, que se midió en número de días a la semana ( 0 días a 7 días).

Fuente: elaboración propia. 
Conversación política interactiva. Se buscó detectar en qué medida los participantes habían mantenido conversaciones sobre política a través de la red durante la campaña electoral. Para ello, se usó la escala que utilizaron en su estudio Yamamoto, Kushin y Dalisay (2015) y que está compuesta por cinco ítems que evalúan actividades como «escribir sobre asuntos políticos en la web» o «participar en discusiones políticas a través de la red». Todos ellos fueron medidos mediante escalas de Likert de 5 puntos, entre nunca (1) y muy seguido (5) $(M=2.47 ; D E=1.18: \alpha=.90)$.

Cinismo político. Para medir la dimensión de cinismo político que se incluye dentro de la desafección política, se utilizó la escala planteada en su estudio por Yamamoto y Kushin (2014), consistente en cinco reactivos como, por ejemplo, «las propuestas de los candidatos en elecciones sólo dependen de cómo les vaya en las encuestas»o «los políticos en elecciones nunca dicen la verdad acerca de sus metas y objetivos». Para su medición, se preguntó a los participantes qué tan de acuerdo estaban con cada una de ellas, a través de una escala de Likert de 6 puntos que oscilaba entre totalmente en desacuerdo (1) y totalmente de acuerdo (6) $(M=4.81 ; D E=0.98 ; \alpha=.89)$.

Apatía política. Por su parte, la dimensión de apatía política perteneciente a la escala de desafección política fue medida igualmente a partir de la propuesta realizada por Yamamoto y Kushin (2014). En particular, se preguntó a los participantes qué tan de acuerdo estaban, a partir de una escala de Likert de 6 puntos que oscilaba entre totalmente en desacuerdo (1) y totalmente de acuerdo (6), con cuatro afirmaciones como las siguientes: «votar toma mucho tiempo» o «es muy complicado estar informado acerca de política» $(M=3.12 ; D E=1.14 ; \alpha=.73)$.

Escepticismo político. La dimensión de la desafección política relativa al nivel de escepticismo político de los ciudadanos fue medida, igualmente, a partir de la propuesta realizada por Yamamoto y Kushin (2014). Así, se preguntó a los participantes su grado de acuerdo, a partir de una escala de Likert de 6 puntos que oscilaba entre totalmente en desacuerdo (1) y totalmente de acuerdo (6), con cinco afirmaciones tales como, por ejemplo, «reflexiono sobre las cosas que los políticos dicen antes de aceptarlas como ciertas» o «evaluó críticamente las declaraciones hechas por los políticos» $(M=4.83$ : $D E=0.92 ; \alpha=.92$ ).

Variables de control. Finalmente, se contempló el uso de una serie de variables de control de carácter sociodemográfico. En concreto, se les cuestionó a los participantes acerca de su género $(0=$ masculino; $1=$ femenino $)$ y su edad, en años cumplidos. También se pidió que indicaran cuál era, aproximadamente, el nivel de ingresos mensual de su núcleo familiar, con una escala que oscilaba entre menos 
de 6.000 pesos mexicanos (1) y más de 30.001 pesos mexicanos (4). También, se evaluó de forma adicional el nivel de estudios de los participantes, con una escala que osciló entre no tiene (1) y estudios de posgrado (7). Finalmente, se utilizó la escala de confianza en información de medios planteada por Miller y Krosnick (2000), adaptada por Muñiz y Maldonado (2011), para medir el grado de confianza con las noticias publicadas por los medios de comunicación. Mediante una escala Likert de 6 puntos (nada a bastante) se preguntó el grado de acuerdo con afirmaciones como «las noticias a menudo cuentan los hechos de una forma inexacta o poco correcta» $(M=2.37 ; D E=1.16 ; \alpha=.79)$.

Tabla 2 Correlaciones parciales de las variables utilizadas en el modelo.

\begin{tabular}{|c|c|c|c|c|c|c|c|c|}
\hline Variables del estudio & 1 & 2 & 3 & 4 & 5 & 6 & 7 & 8 \\
\hline Interés Político & & $.242^{\star * \star}$ & $.373^{* * *}$ & $.359^{* * *}$ & $.333^{* * *}$ & .005 & $-.133^{\star \star *}$ & $.241^{* * *}$ \\
\hline Consumo de medios tradicionales & & & $.552^{* \star *}$ & $.504^{\star \star \star}$ & $.509^{* * *}$ & -.019 & $.152^{* \star *}$ & $.093^{*}$ \\
\hline Seguimiento de medios sociales & & & & $.575^{\star \star \star}$ & $.691^{* * *}$ & -.062 & -.038 & $.200^{* * *}$ \\
\hline Conversación política interpersonal & & & & & $.651^{* * *}$ & -.005 & -.010 & $.199^{* \star *}$ \\
\hline Conversación política interactiva & & & & & - & $-.091^{*}$ & .019 & $.168^{* * *}$ \\
\hline Cinismo político & & & & & & - & $.243^{* \star *}$ & $.376^{* * \star}$ \\
\hline Apatía política & & & & & & & - & -.043 \\
\hline Escepticismo político & & & & & & & & \\
\hline
\end{tabular}

Nota: $N=701 .{ }^{*} p<.05 ;{ }^{* \star *} p<.001$

Fuente: elaboración propia.

\section{Análisis de los Resultados}

Como primer paso del análisis, se revisó la existencia de relaciones entre las diferentes variables contempladas en el estudio (ver tabla 2). El análisis permitió determinar si existían o no correlaciones entre las variables, y descartar así posibles problemas de colinealidad entre algunas de ellas, que se asumen en caso de existir correlaciones superiores a $r=.90$ y que explican similitudes grandes entre dos o más variables que llevan a generar problemas en el grado explicativo del modelo planteado. Para ello, se trabajó con correlaciones parciales, que permiten controlar la influencia de las variables de control en las correlaciones orden cero de los demás indicadores. Como se puede observar en los datos obtenidos, la correlación parcial más alta encontrada fue la existente entre el seguimiento de medios sociales y la conversación política interactiva, $r_{\text {parcial }}(645)=.691$; 
$p<.001$, por lo que se pueden descartar problemas de colinealidad en los datos utilizados.

Destaca, sin embargo, el hecho de que no se encontraran relaciones significativas entre el cinismo y las variables de interés, consumo mediático y conversación política, lo que apunta a una posible falta de viabilidad del modelo estudiado con respecto al cinismo. No obstante, sí se observó una relación entre el cinismo y las restantes dimensiones de la desafección. En este sentido, se encontró una asociación estadísticamente significativa y positiva del cinismo, tanto con la apatía política, $r_{\text {parcial }}(645)=.243 ; p<.001$, como con el escepticismo político, $r_{\text {parcial }}(645)=.376 ; p<.001$. Este resultado parece sugerir la existencia de la espiral de desafección planteada en la teoría, sobre todo cuando se observa que apatía y escepticismo no correlacionaron entre sí. Para responder a la primera pregunta de investigación, se compararon las dos correlaciones significativas, hallándose una mayor asociación del cinismo con el escepticismo que con la apatía, $Z=2.75 ; p=.006$.

Figura 2. Impacto en cinismo político a través de medios y conversación tradicionales.

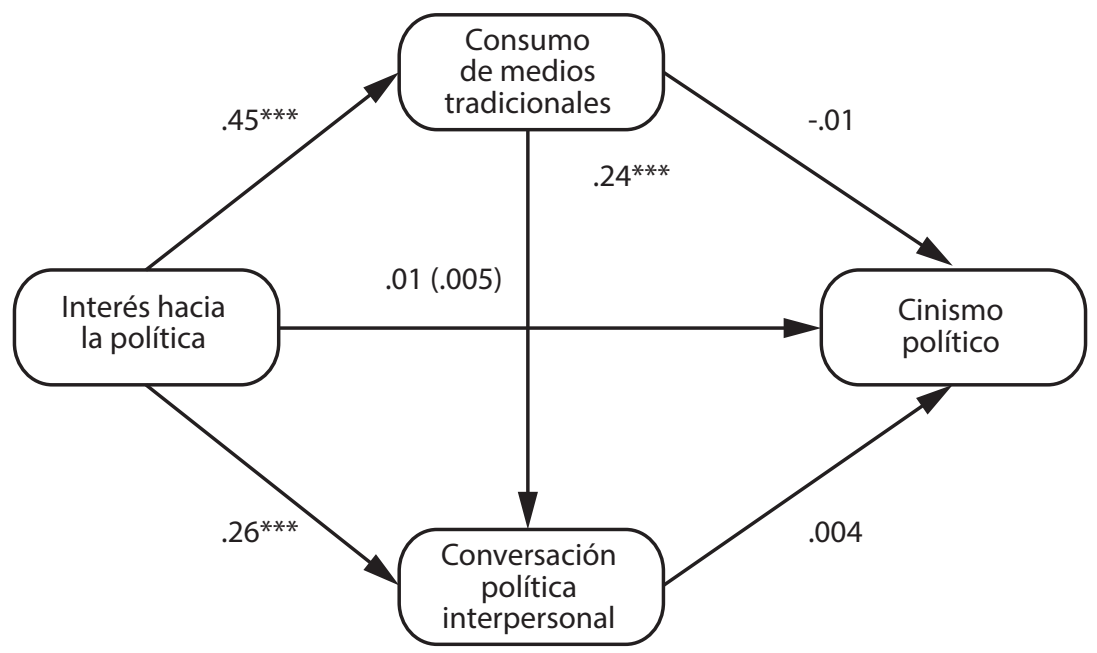

Nota: $N=652 .{ }^{* * *} p<.001$

Fuente: elaboración propia

Posteriormente, y para probar el modelo teórico propuesto con las diferentes variables del estudio, se procedió a realizar los análisis mediacionales, utilizando para ello como variable independiente el interés hacia la política manifestado por los participantes en la ola primera, antes de comenzar la campaña electoral. Como variable dependiente se tomaron las diferentes dimensiones de la desafección política, conforme fueron explicadas en la 
metodología, a partir de la medición de la tercera ola. Además, se utilizaron como variables mediadoras el consumo durante la campaña para informase de las elecciones presidenciales, así como las variables de conversación política interpersonal e interactiva, todas ellas medidas en la segunda ola del estudio. A su vez, se controlaron las diferentes variables sociodemográficas contempladas para evitar su efecto en el modelo.

Para realizar el análisis mediacional, se utilizó la macro PROCESS para SPSS creada por Hayes (2013), que permite calcular los efectos directos (de la predictora sobre la variable criterio, controlando las mediadoras), indirectos (de la predictora sobre la variable criterio a través de las mediadoras) y totales (suma de los anteriores efectos) en el modelo propuesto. En particular se trabajó el modelo 6, con un bootstrapping de 10.000 muestras, que permite determinar si los modelos de cadena causal propuestos presentan algún efecto indirecto sobre la variable dependiente. En este sentido, se calculó en primer lugar el modelo O-S-R-O con el cinismo político como variable criterio y el consumo y conversación tradicionales como mediadoras (ver figura 2). Al respecto, no se detectó ningún efecto indirecto, ni a través del consumo de medios, ni de la conversación política, ni de ambos mediadores en conjunto.

Figura 3. Impacto en apatía política a través de medios y conversación tradicionales.

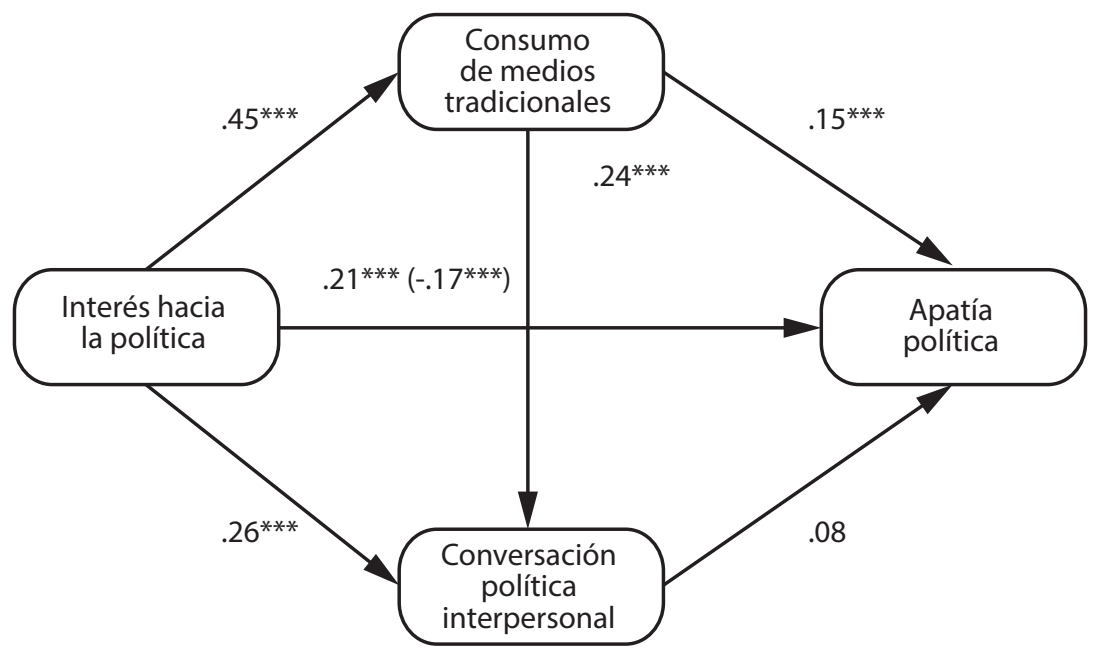

Nota: $N=652 .{ }^{* * *} p<.001$

\section{Fuente: elaboración propia.}

Por su parte, también se analizó el modelo teórico propuesto con la apatía política como variable criterio, y actuando de nuevo como mediadores la conversación y consumo de medios tradicionales (ver figura 3). 
En este caso, no se detectó un efecto indirecto a través de la conversación política interpersonal, ni de ambos mediadores en conjunto a través de un proceso de cadena causal, pero sí a través del consumo de medios tradicionales, $B=.07 ; E T=.0182 ; 95$ por ciento IC [.0377; .1098]. Así, $\mathrm{y}$ en respuesta a la pregunta segunda, se puede concluir que el interés hacia la política llevó a los participantes a consumir más medios tradicionales para informarse de las elecciones $(\beta=.45 ; p<.001)$, lo que a su vez contribuyó en un aumento de la apatía política $(\beta=.15$; $p<.001)$. Esto a pesar de que, a priori, el interés tendía a hacer disminuir la apatía manifestada por los participantes $(\beta=-.21 ; p<.001)$.

Finalmente, dentro de la evaluación del modelo que asume como variables mediadoras el consumo y conversación offline, se contrastó el impacto del interés hacia la política sobre el escepticismo político de los participantes (ver figura 4). Al respecto, aunque no se detectó un efecto indirecto a través del consumo de medios tradicionales, sí se halló a través de la conversación política interpersonal como variable mediadora, $B=.03 ; E T=.0130 ; 95$ por ciento IC [.0122; .0642], y de ambos mediadores en conjunto a través de un proceso de cadena causal, $B=.015 ; E T=.0057 ; 95$ por ciento IC $[.0050 ; .0277]$. El contraste de ambos efectos indirectos permitió determinar que fue el primero el que mejor explicó. Por tanto, y en respuesta a la pregunta tercera, se puede concluir que el interés llevó a los participantes a conversar de forma interpersonal sobre las elecciones $(\beta=.26 ; p<.001)$, lo que a su vez contribuyó en un incremento del escepticismo político $(\beta=.13 ; p=.002)$.

Figura 4. Impacto en escepticismo político a través de medios y conversación tradicionales.

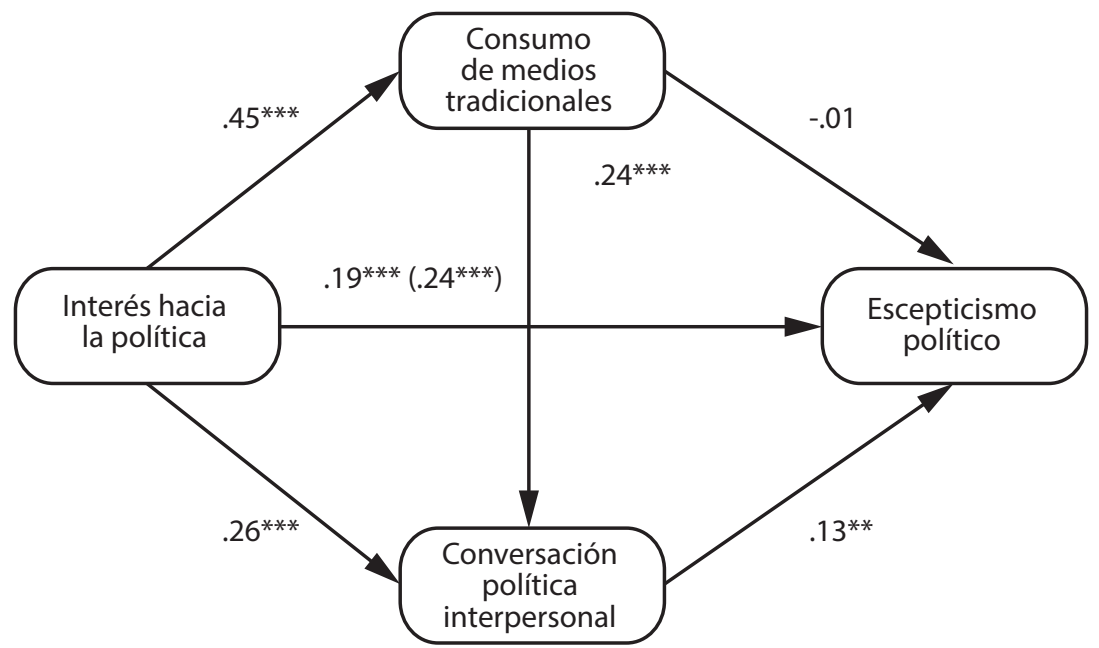

Nota: $N=652 .{ }^{* *} p<.01 ;{ }^{* * *} p<.001$ 
Fuente: elaboración propia.

En cuanto a la evaluación del modelo que asume como variables mediadoras el consumo y la conversación online y el cinismo político como variable dependiente, no se contrastó un impacto directo o indirecto del interés hacia la política sobre el mismo (ver figura 5).

Figura 5. Impacto en cinismo político a través de medios y conversación online.

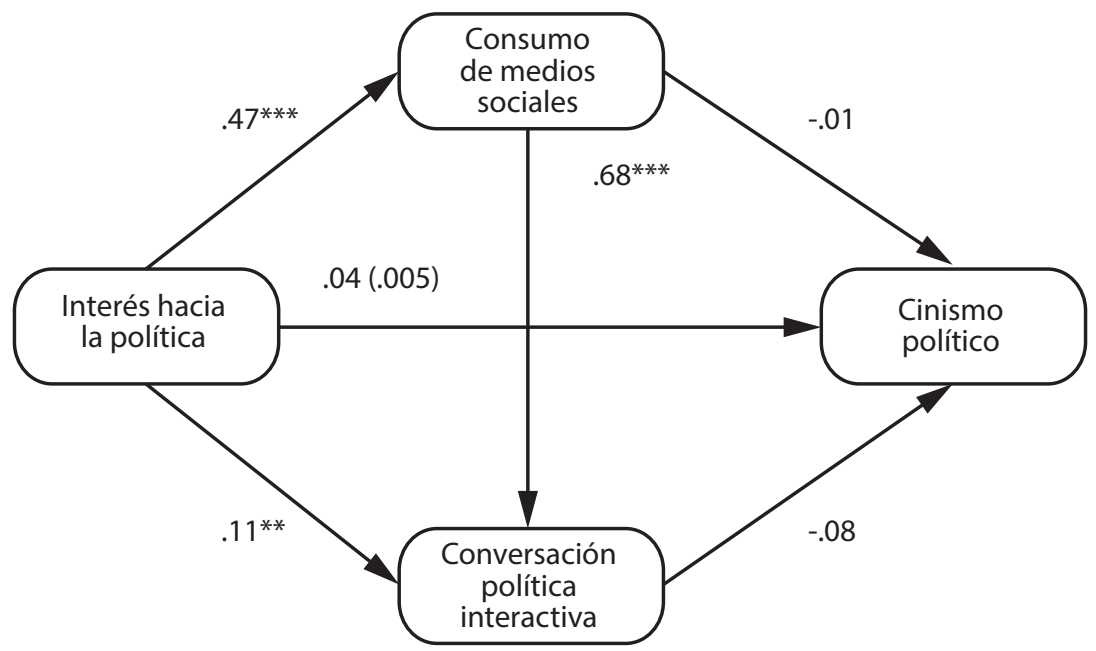

Nota: $N=652 .{ }^{* *} p<.01 ;{ }^{* * *} p<.001$

Fuente: elaboración propia.

Sin embargo, sí se detectaron efectos indirectos con respecto a la explicación de la apatía política (ver figura 6). En este sentido, no se observó un efecto indirecto a través del consumo de medios sociales ni de ambos mediadores en conjunto a través de un proceso de cadena causal, pero sí a través de la conversación política interactiva como variable mediadora, $B=.012$; $E T=.0090 ; 95$ por ciento IC $[.0001 ; .0366]$. Así pues, y en respuesta a la pregunta cuarta, se puede concluir que el interés hacia la política llevó a los participantes a aumentar su conversación política interactiva $(\beta=.11$; $p=.005)$, impactando a su vez en un incremento de la apatía política $(\beta=.10 ; p=.047)$. Cabe resaltar que, en similitud al modelo de apatía antes estudiado, el interés tendía a priori a hacer disminuir la apatía manifestada por los participantes $(\beta=-.10 ; p<.001)$. 
Figura 6. Impacto en apatía política a través de medios y conversación online.

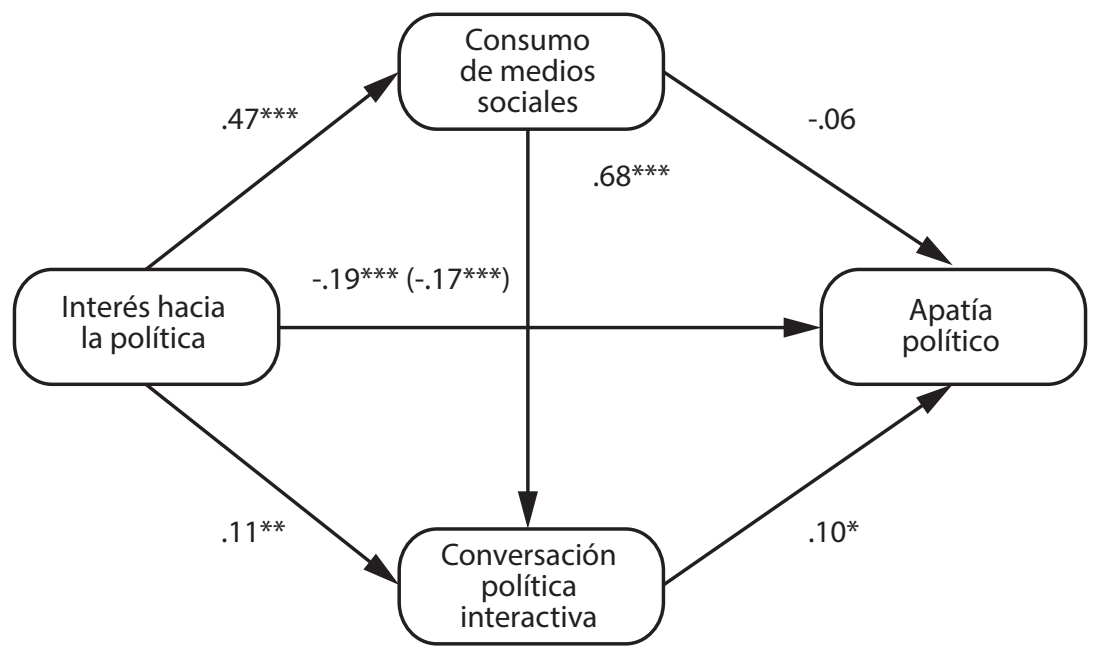

Nota: $N=652 .{ }^{*} p<.05 ;{ }^{* *} p<.01 ;{ }^{* * *} p<.001$

Fuente: elaboración propia.

Figura 7. Impacto en escepticismo político a través de medios y conversación online.

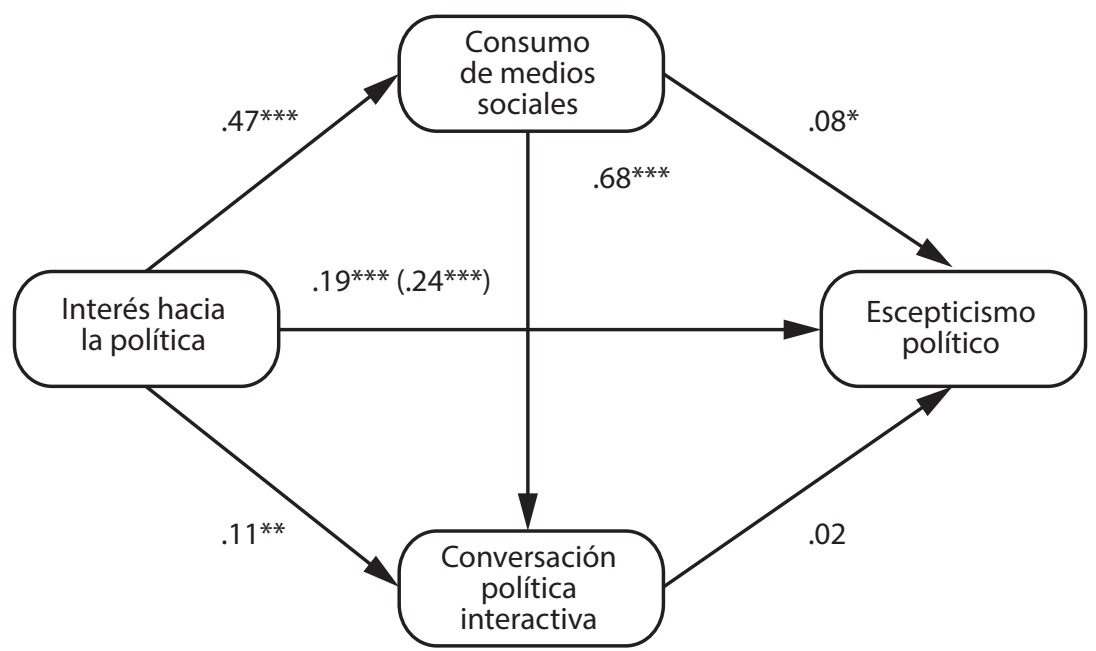

Nota: $N=652 .{ }^{*} p<.05 ;{ }^{* *} p<.01 ;{ }^{* * *} p<.001$

Fuente: elaboración propia.

Finalmente, se evaluó la aplicabilidad del modelo teórico a la explicación del escepticismo político, asumiendo como variables mediadoras el consumo de medios y la conversación política realizados en el terreno digital (ver figura 7). Al respecto, no se detectó ningún efecto indirecto, ni a través de 
la conversación política interactiva, ni a través del seguimiento de medios sociales durante la campaña electoral, ni de ambos mediadores en conjunto para informarse de las elecciones presidenciales. Así pues, y en respuesta a la pregunta quinta, se puede concluir que el interés hacia la política influyó de forma directa en un aumento del escepticismo $(\beta=.19 ; p<.001)$, pero no gracias al consumo mediático o conversación sobre política.

\section{Discusión y conclusiones}

El presente estudio buscaba, como se señaló anteriormente, determinar en qué medida el proceso de influencia mediática en las actitudes políticas planteado desde el modelo O-S-R-O-R (Muñiz et al., 2017; Shah et al., 2005, 2017) se presentó durante las elecciones presidenciales de México de 2018. Y, más en concreto, si se podía asumir la existencia de un proceso mediacional para explicar el impacto del interés hacia la política en la desafección política de la ciudadanía - en sus diferentes dimensiones - a través del papel desarrollado por las prácticas comunicativas offline y online, tanto de consumo mediático como de conversación política. Para ello, primero se evaluó la relación entre las variables utilizadas en el modelo, para posteriormente realizar los diferentes análisis mediacionales con las mismas, al objeto de resolver las preguntas e hipótesis planteadas.

En relación con la primera pregunta de investigación del estudio, ésta derivaba del planteamiento teórico acerca de la existencia de una espiral de desafección política (Austin y Pinkleton, 1995; Rijkhoff, 2018), que conlleva que la disposición negativa hacia la política que implica el cinismo político pueda derivar en resultados negativos, como la apatía, o en positivas, como el escepticismo (Yamamoto y Kushin, 2014). Ante el cuestionamiento realizado en este artículo, se puede concluir la existencia de este proceso de desafección, en tanto que se observó una asociación entre la variable de cinismo político tanto con la de apatía como la de escepticismo, que desde el modelo de espiral antes descrito serían sus resultantes. Sin embargo, y en coherencia con el planteamiento teórico de la espiral, no se observó una asociación entre escepticismo y apatía.

Este resultado hace aflorar la existencia de dos perfiles entre aquellos ciudadanos que, a priori, comparten el alejamiento de la política y del sistema que se manifiesta en su cinismo político. Es decir, se puede concluir la existencia de ese cinismo comprometido, señalado en su trabajo por Muñiz y Maldonado (2011) respecto a los estudiantes de bachillerato, pero ahora referido a la población general. Ello, frente a un cinismo anómico o negativo, se manifiesta en una apatía y un alejamiento de la política presente en buena 
parte de la población que, sin dejar de tener recelo respecto al sistema político, sin embargo, decide comprometerse con éste, recabando información complementaria y, posiblemente, participando para lograr el cambio. Una realidad que parece haberse dado en México, durante y tras las elecciones presidenciales de 2018, atendiendo al clima de optimismo que los datos demoscópicos recientes apuntan (Corduneanu, 2019).

En relación con las hipótesis planteadas sobre el efecto del modelo en el cinismo político, no se detectó un efecto indirecto del interés político, ni a través del consumo de medios, ni de la conversación política. Como se pronosticó a la luz de los estudios precedentes (Choi et al., 2018), no se pudo comprobar el modelo propuesto, ni en el escenario de comunicación tradicional, ni en el de procesos comunicativos en el ámbito online. Estos resultados ponen de manifiesto cómo esta dimensión de la desafección política sigue siendo relativamente poco afectada por los medios de comunicación. Tal y como ha sido cuestionado por otros autores (revisar al respecto los señalados por Muñiz y Maldonado, 2011; Rojas, 2006), los medios no parecen generar una espiral del cinismo, pero ello no quiere decir que esta brecha no exista. Más bien, parece que son otros factores externos los que pueden ayudar a que el cinismo aumente o disminuya.

En cuanto a las preguntas de investigación planteadas con relación a la apatía política de la ciudadanía, se encontraron resultados que confirmaron en parte el modelo, tanto en el terreno offline como online. Con relación a ello, es interesante apuntar cómo el consumo de medios tradicionales para seguir la campaña electoral tuvo la capacidad de condicionar la apatía de la ciudadanía, sin el necesario ejercicio de la reflexión posterior con relación a la información recibida que implica la conversación. En cuanto al mundo digital, fue la conversación política interactiva desarrollada por los ciudadanos la que impactó, de forma positiva, en el incremento de la apatía política. Estos resultados ponen de manifiesto que el modelo mediacional comunicativo propuesto a nivel teórico no fue el que mejor se adaptó para explicar la apatía, pues en ninguno de los casos la cadena causal de prácticas comunicativas fue el mejor modelo explicativo.

En cualquier caso, y al respecto de este resultado acerca de la apatía, se detectó en ambos modelos mediacionales un efecto indirecto negativo de las prácticas comunicativas sobre esta dimensión de la desafección. Y es que, en ambos casos, la incorporación del consumo de medios tradicionales o de conversación política interactiva, modificó la influencia inicial beneficiosa del interés sobre la apatía política. Este resultado pone de manifestó cómo las prácticas comunicativas tienen la capacidad, no sólo de incrementar la desmo- 
vilización política que representa la apatía, sino incluso de modificar el efecto positivo que un compromiso afectivo previo tiene - como el que representa el interés con la política - sobre la configuración de una ciudadanía más comprometida. Un resultado que no deja de alimentar la idea de esa espiral de desafección anteriormente expuesta (Rijkhoff, 2018).

Finalmente, y en relación al escepticismo político, se plantearon dos preguntas de investigación acerca de la aplicación del modelo de mediación comunicativa para su posible explicación como orientación posterior. Los resultados obtenidos no fueron tan concluyentes como los anteriormente explicados para el caso de la apatía, pues sólo se encontró un modelo mediacional explicativo para el mundo offline, pero no para el mundo digital. En este sentido, se observa cómo la conversación política interpersonal, desarrollada cara a cara, tiene la capacidad de mediar entre el interés político y el escepticismo. Así, aquellos que a priori se sentían más comprometidos afectivamente con la política, tendieron a incrementar su escepticismo tras la conversación con otras personas sobre los asuntos que rigen la agenda política, en el caso de estudio la campaña electoral.

Sin embargo, en el caso de las prácticas comunicativas desarrolladas en el mundo digital, no se comprobó el modelo mediacional propuesto. Ello no deja de ser relevante, sobre todo cuando se asume la existencia de una fuerte presencia de los medios sociales y prácticas comunicativas online en el contexto de las nuevas campañas electorales (Boomgaarden y Kritzinger, 2017). Más allá de este resultado, se puede concluir que el consumo de medios en términos generales tiene un impacto beneficioso en el desarrollo de públicos que plantean dudas respecto de la información que reciben y que buscan información adicional sobre la misma para completar su conocimiento, en un proceso de espiral de desafección con resultado más positivo (Yamamoto y Kushin, 2014), lo que puede ser beneficioso para la democracia. Unos resultados que, en cualquier caso, deben seguir siendo analizados en estudios posteriores.

\section{Referencias}

Ackerman, J. M. (2012). Autenticidad y nulidad. Por un derecho electoral al servicio de la democracia. Ciudad de México: UNAM.

Agger, R. E.; Goldstein, M. N. y Pearl, S. A. (1961). Political Cynicism: Measurement and Meaning. The Journal of Politics, 23(3), 477-506. Doi: hittp://doi.org/10.2307/2127102

Austin, E. W. y Pinkleton, B. E. (1999). The Relation Between Media Content Evaluations and Political Disaffection. Mass Communication and Society, 2(3-4), 105-122. Doi: http://doi.org/10.1080/15205436.1999.9677867 
Austin, E. W. y Pinkleton, B. E. (1995). Positive and negative effects of political disaffection on the less experienced voter. Journal of Broadcasting \& Electronic Media, 39(2), 215-235. Doi: http://doi.org/10.1080/08838159509364300

Avery, J. M. (2009). Videomalaise or Virtuous Circle? The Influence of the News Media on Political Trust. The International Journal of Press/Politics, 14(4), 410-433. Doi: http://doi.org/10.1177/1940161209336224

Bakker, T. P., \& de VReese, C. H. (2011). Good News for the Future? Young People, Internet Use, and Political Participation. Communication Research, 38(4), 451-470. Doi: http://doi.org/10.1177/0093650210381738

BoomgaArden, H. G. y Kritzinger, S. (2017). Election Surveys. En J. MatThes (Ed.), The International Encyclopedia of Communication Research Methods (pp. 1-9). NJ, USA: John Wiley \& Sons, Inc. Doi: http://doi.org/10.1002/9781118901731.iecrm0077

Cappella, J. N. y Jamieson, K. H. (1997). Spiral of cynicism : the press and the public good. New York: Oxford University Press.

Choi, H.; Warner, B. R. y Jennings, F. J. (2018). What Mobilizes Partisans? Exploring the Underlying Pathways Between Partisan Media and Political Participation. En B. R. Warner; D. G. Bystrom; M. S. McKinney y M. C. BANWART (Eds.), An unprecedented election: media, communication, and the electorate in the 2016 campaign (pp. 40-61). Santa Barbara, CA: Praeger.

Corduneanu, V. I. (2019). El papel de las emociones sociales y personales en la participación política. Revista Mexicana de Opinión Pública, (26), 71-96. Doi: http://doi.org/10.22201/fcpys.24484911e.2019.26.66903

Corduneanu, V. I. y MuÑIZ, C. (2011). ¿Autoritarismo superado? Medios y actitudes políticas en el contexto mexicano. En C. MuÑIz (Ed.), Comunicación, Política y Ciudadanía. Aportaciones actuales al estudio de la comunicación política (pp. 283-307). Ciudad de México: Fontamara.

Dalton, R. J. (2006). Citizen politics : public opinion and political parties in advanced industrial democracies. Washington, DC: CQ Press.

Dalton, R. J. (2004). Democratic Challenges, Democratic Choices: The Erosion of Political Support in Advanced Industrial Democracies. Oxford: Oxford University Press. Doi: http://doi.org/10.1093/acprof:oso/9780199268436.001.0001

de VReese, C. H. (2005). The Spiral of Cynicism Reconsidered. European Journal of Communication, 20(3), 283-301. Doi: http://doi.org/10.1177/0267323105055259

de Vreese, C. H. y Semetro, H. A. (2002). Cynical and Engaged: Strategic Campaign Coverage, Public Opinion, and Mobilization in a Referendum. Communication Research, 29(6), 615-641. Doi: http://doi.org/10.1177/009365002237829 Delli Carpini, M. X. (2004). Mediating Democratic Engagement: The Impact of Communications on Citizens' Involvement in Political and Civic Life. En L. L. KAID (Ed.), Handbook of political communication (pp. 395-434). New York: Lawrence Erlbaum. 
Delli Carpini, M. X. (2000). Gen.com: Youth, Civic Engagement, and the New Information Environment. Political Communication, 17(4), 341-349. Doi: http://doi.org/10.1080/10584600050178942

Dimitrova, D. V. y StrömbäcK, J. (2012). Election news in Sweden and the United States: A comparative study of sources and media frames. Journalism, 13(5), 604-619. Doi: http://doi.org/10.1177/1464884911431546

Gil de ZÚNĩgA, H.; BachmanN, I.; Hsu, S.-H. y BRundidge, J. (2013). Expressive Versus Consumptive Blog Use: Implications for Interpersonal Discussion and Political Participation. International Journal of Communication, 7 , 1538-1559.

Gil de Zúñiga, H.; Jung, N. y Valenzuela, S. (2012). Social Media Use for News and Individuals' Social Capital, Civic Engagement and Political Participation. Journal of Computer-Mediated Communication, 17(3), 319-336. Doi: hittp://doi.org/10.1111/j.1083-6101.2012.01574.x

HAYES, A. F. (2013). Introduction to Mediation, Moderation, and Conditional Process Analysis: A Regression-Based Approach. New York, NY.: The Guilford Press.

Holtz-Bacha, C. (1990). Videomalaise Revisited: Media Exposure and Political Alienation in West Germany. European Journal of Communication, 5(1), 73-85. Doi: http://doi.org/10.1177/0267323190005001005

JunG, N.; KIM, Y. y GIL DE ZÚÑIGA, H. (2011). The Mediating Role of Knowledge and Efficacy in the Effects of Communication on Political Participation. Mass Communication and Society, 14(4), 407-430. Doi: http://doi.org/10.1080/15205436.2010.496135

Kıм, Y.; Russo, S. y AmNA, E. (2017). The longitudinal relation between online and offline political participation among youth at two different developmental stages. New Media \& Society, 19(6), 899-917. Doi: http://doi.org/10.1177/1461444815624181

Lee, N. J.; Shah, D. V. y McLeod, J. M. (2013). Processes of Political Socialization. Communication Research, 40(5), 669-697. Doi: http://doi.org/10.1177/0093650212436712

Luján Ponce, N. y García Villanueva, C. (2007). Ciudadanos educados, ciudadanos desconfiados. Veredas, 8(14), 167-188.

Martínez, F. J. y Godínez, F. A. (2013). La Agenda de los telediarios en la contienda del 2012. Derecho a Comunicar, (7), 59-75.

Miller, J. M. y Krosnick, J. A. (2000). News Media Impact on the Ingredients of Presidential Evaluations: Politically Knowledgeable Citizens Are Guided by a Trusted Source. American Journal of Political Science, 44(2), 301. Doi: http://doi.org/10.2307/2669312

Mora Heredia, J. y Escobar Cruz, C. (2003). Política y cultura. Política y Cultura, (19), 127-144. 
MuñIZ, C. y Corduneanu, V. I. (2014). El papel mediador de la conversación política en la generación de participación política: evidencias desde una perspectiva generacional comparativa. En G. Meixueiro y A. Moreno (Eds.), El comportamiento electoral mexicano en las elecciones de 2012 (pp. 201-228). Ciudad de México: CESOP.

MuÑIz, C. y MaLdonado, L. (2011). Entre la movilización y el malestar mediático. Impacto de las prácticas comunicativas en las actitudes políticas de los jóvenes. Perspectivas de La Comunicación, 4(2), 32-54.

MuÑIz, C.; TéLlez, N. M. y SAldierna, A. R. (2017). Political sophistication as a mediator in the relation between media consumption and citizen participation. Evidence from the O-S-R-O-R model. Communication and Society, 30(3). Doi: http://doi.org/10.15581/003.30.3.255-274

Norris, P. (2000). A Virtuous Circle: Political Communication in Post-industrial Democracies. Oxford, UK: Oxford University Press.

Paramio, L. (2002). La globalización y el malestar en la democracia. Revista Internacional de Filosofia Política, (20), 5-23.

Pharr, S. J. y Putnam, R. D. (2000). Disaffected Democracies: What's Troubling the Trilateral Countries? New Jersey: Princeton University Press.

RiJkhoff, S. A. M. (2018). Still Questioning Cynicism. Society, 55(4), 333-340. Doi: http://doi.org/10.1007/s12115-018-0264-8

Rojas, H. (2006). Comunicación, participación y democracia. Universitas Humanística, 62, 109-142.

Saldierna, A. R.; Marañón, F. de J. y MuñIz, C. (2015). El papel de la comunicación en la generación de interés y conocimiento político entre los preciudadanos. Aplicación del modelo O-S-R-O-R al caso mexicano. Revista Mexicana de Opinión Pública, (19), 147-165. Doi: http://doi.org/10.1016/.j.rmop.2015.03.003

Schuck, A. R. T.; Boomgaarden, H. G. y de VReese, C. H. (2013). Cynics All Around? The Impact of Election News on Political Cynicism in Comparative Perspective. Journal of Communication, 63(2), 287-311. Doi: http://doi.org/10.1111/jcom.12023

Secretaría de Gobernación. (2012). V Encuesta Nacional sobre Cultura Política y Prácticas Ciudadanas (ENCUP). Ciudad de México: SEGOB.

Shah, D. V.; Cho, J.; Eveland, W. P. y Kwak, N. (2005). Information and Expression in a Digital Age. Communication Research, 32(5), 531-565. Doi: http://doi.org/10.1177/0093650205279209

Shah, D. V.; Cho, J.; Nah, S.; Gotlieb, M. R.; Hwang, H.; Lee, N.-J. y McLeod, D. M. (2007). Campaign Ads, Online Messaging, and Participation: Extending the Communication Mediation Model. Journal of Communication, 57(4), 676-703. Doi: http://doi.org/10.1111/j.1460-2466.2007.00363.x 
Shah, D. V.; McLeod, D. M.; Rojas, H.; Cho, J.; Wagner, M. W. y Friedland, L. A. (2017). Revising the Communication Mediation Model for a New Political Communication Ecology. Human Communication Research, 43(4), 491-504. Doi: http://doi.org/10.1111/hcre.12115

Torcal, M. (2002). Institutional Disaffection and Democratic History in New Democracies. Central European Political Science Review, 3(10), 40-77.

TREJo, R. (1994). ¿Videopolítica vs. mediocracia? Los medios y la cultura democrática. Revista Mexicana de Sociología, 56(3), 23-58. Doi: http://doi.org/10.2307/3540847

VAlenZuela, S. (2013). Unpacking the Use of Social Media for Protest Behavior. American Behavioral Scientist, 57(7), 920-942. Doi: http://doi.org/10.1177/0002764213479375

Valenzuela, S.; Park, N. y Kee, K. F. (2009). Is There Social Capital in a Social Network Site?: Facebook Use and College Students' Life Satisfaction, Trust, and Participation. Journal of Computer-Mediated Communication, 14(4), 875-901. Doi: http://doi.org/10.1111/j.1083-6101.2009.01474.x

Yamamoto, M. y Kushin, M. J. (2014). More Harm Than Good? Online Media Use and Political Disaffection Among College Students in the 2008 Election. Journal of Computer-Mediated Communication, 19(3), 430-445. Doi: http://doi.org/10.1111/jcc4.12046

Yamamoto, M.; Kushin, M. J. y Dalisay, F. (2015). Social media and mobiles as political mobilization forces for young adults: Examining the moderating role of online political expression in political participation. New Media \& Society, 17(6), 880-898. Doi: http://doi.org/10.1177/1461444813518390

Para citar este artículo: Muñiz, C. (2019). Prácticas comunicativas y desafección política en el contexto de las campañas electorales. Análisis de su relación desde el modelo O-S-R-O-R. index.comunicación, 9(1), 80-107. 